\title{
Maritime trade in the Indian Ocean: value- focused thinking for BRI and CPEC by employing A'WOT hybrid technique
}

\author{
Alexey Mikheev ${ }^{1}$, Kanwar Muhammad Javed Iqbal $^{2,}{ }^{*}$, Irina Kapustina ${ }^{3}$, and Amen Butt ${ }^{4}$ \\ ${ }^{1}$ Moscow State Institute of International Relations (University) of the Ministry of Foreign Affairs of \\ the Russian Federation, Moscow, Russia \\ ${ }^{2}$ National Institute of Maritime Affairs, Bahria University, Sector E-8, 44000 Islamabad, Pakistan \\ ${ }^{3}$ Peter the Great St. Petersburg Polytechnic University, 195251, St. Petersburg, Russia \\ ${ }^{4}$ Free-lance Professional, 44000 Islamabad, Pakistan
}

\begin{abstract}
Belt and Road Initiative (BRI) and China Pakistan Economic Corridor (CPEC) have so far developed the narrative of bringing prosperity and peace; particularly in the welfare context of Afro-Asian population in Indian Ocean littoral states and enhanced cooperation among countries in Asia, Europe and Africa. The grey areas needs to be analysed with ValueFocused Thinking (VFT) for the overall discourse of maritime. Thus, this study examined the emerging role of BRI viz-a-viz trade opportunities and challenges for Pakistan and China by employing A'WOT method. Results reveal that the successful BRI and CPEC endeavours will open up a door for future investment, prosperity and sustainable development in Indian Ocean Region (IOR). However, Pakistan has higher ratio of threats compare to China and relative to the opportunities considering the weaknesses due to internal and external factors. Maritime trade under BRI has success potential due to geo-strategic location of Pakistan and weaknesses can be avoided in a complete decision support manner with appropriate policy and strategic arrangements.
\end{abstract}

\section{Introduction}

Indian Ocean Region (IOR), the world's most important maritime trade route, has gained much significance and will become the major economic hub with the passage of time [1]. Almost two-thirds of global oil shipment transportation is from the Persian Gulf, an IOR territory, and covers an estimated $40 \%$ of the world's offshore oil production [2]. Almost 90 percent of the world's trade is dependent on sea routes [3]. Maritime trade in the Western Indian Ocean has gained much importance after launching the BRI and CPEC which is the main catalyst of strategic realignment [3] and so far developed the narrative of bringing prosperity with enhanced cooperation among countries in Asia, Europe and Africa [4,5]. BRI consists of three important routes i.e. Southern, Central and Northern. The southern passage links Western side of China with Gwadar harbour in the Arabian Sea [6]. The main transit point Gwadar is tail of BRI, which is located nearby the Strait of Hormuz through which one-

*Corresponding author: kanwar.javediqbal@gmail.com 
third of world's oil is traded. Gwadar is likely to play a significant role in energy security of Western China by offering a much shorter route than ever before used by Chinese [7], reducing its current maritime transportation distance from $12000 \mathrm{~km}$ to $3000 \mathrm{~km}$ [8] and also reducing its existing dependence on the Strait of Malacca [9]. This is more likely a game changer project for taking out millions of people from misery and poverty. It will produce employment because it embraces the construction of industrial parks, textile garments and construction of dams in Pakistan. In the underdeveloped area, this project will provide the networks of rails and road transport system.

Development of maritime trade under BRI and CPEC is categorically important for economic growth of Pakistan, China, IOR region and beyond. It is observed that many queries and contradictory arguments are under discussion among global intellectual circles which need to be unfolded. At the same time, there exists some threats, fears, and conspiracies in the backdrop of geopolitics of the Western Indian Ocean region, which needs to be assessed at this very stage of the development. In the context, this study explored the overall discourse of maritime trade as a win-win-scenario for both China and Pakistan. This study also evaluates the pros \& cons by identifying the grey areas for decision analysis viza-viz opportunities and threats. It also demonstrates the usability of A'WOT which is a pioneering decision analysis tool for maritime trade industry by evaluating the interests of both countries.

\section{Methodology}

This study examined the maritime trade of Western Indian Ocean region in the context of China's BRI and its off-root projects under CPEC through Gwadar Gateway, using VFT approach [10] with A'WOT hybrid method. A'WOT, a combination of SWOT (Strengths, weaknesses, opportunities and threats) and SMART (Simple Multi-attribute Rating Technique), is a novel application to the context of BRI and CPEC. SWOT provides a basic framework [11] for A'WOT based alternate strategies for its respective SWOT factors [12]. It was used in tourism sector [11] and best suitable for situational analysis of strategic affairs $[13,14]$. Earlier, A'WOT with the combination of SWOT and AHP also used for strategic planning process [15]. SMART was used first time in natural resources discipline [16] and since then different methods of SMART have been developed [17].

VFT approach (Fig.1) shows positive impact of BRI and CPEC on maritime trade in the Western Indian Ocean Region. Based on VFT approach and literature review, qualitative content and situational analysis was carried out for the identification of SWOT factors. Subsequently, ranking based analysis was carried out as part of six focused group sessions of experts with a semi-structured questionnaire, at various stages of the study. After detailed discussion, priorities were assigned to the SWOT factors. The SMART version used a fixed number of points i.e. 100 that was allotted to decision elements compared at a particular time; a scale of 01 corresponds to 100 points to specify the relative mutual importance of the factors with respect to the entire A'WOT framework. Considering the importance of expert's knowledge for the business case [12], opinions were taken for the evaluation of scores which are very clearly interpreted so as to avoid any misleading question [18]. Different codes used for the SWOT factors i.e. suffix P and C for Pakistan and China respectively. 


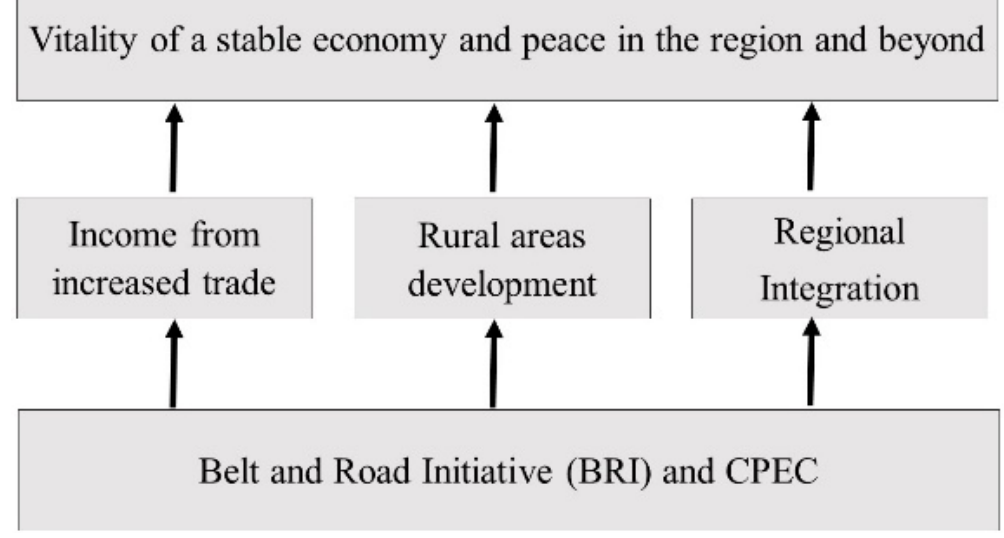

Fig. 1. VFT Approach for BRI \& CPEC.

\section{Results}

The SWOT of this study has taken strengths and weaknesses as an internal factors, whereas opportunities and threats as external factors. Tables 1-2 show A'WOT results, Fig 2 shows comparison of China and Pakistan regading trade in IOR.

Table 1. A'WOT analysis of Pakistan in the context of BRI and CPEC.

\begin{tabular}{|c|c|c|c|}
\hline SWOT Group & $\begin{array}{l}\text { Overall } \\
\text { Priority }\end{array}$ & SWOT Factors & $\begin{array}{l}\text { Priority's } \\
\text { Score }\end{array}$ \\
\hline \multirow{5}{*}{ Strengths } & \multirow{5}{*}{0.30} & SP1: Geo-strategic significance & 0.200 \\
\hline & & SP2: Export oriented economy & 0.040 \\
\hline & & SP3: Fisheries & 0.030 \\
\hline & & SP4: Human Resource Capital & 0.030 \\
\hline & & SP5: Resilient Nation & 0.020 \\
\hline \multirow{4}{*}{ Weaknesses } & \multirow{4}{*}{0.30} & WP1: Poor Governance & 0.120 \\
\hline & & WP2: Lack of transparency & 0.120 \\
\hline & & WP3: Lack of Quality Labour Force & 0.030 \\
\hline & & WP4: Geographical obstacles & 0.030 \\
\hline \multirow{8}{*}{ Opportunities } & \multirow{8}{*}{0.15} & $\begin{array}{l}\text { OP1: Development of Ports and } \\
\text { Infrastructure }\end{array}$ & 0.030 \\
\hline & & $\begin{array}{l}\text { OP2: Development of Shipping and } \\
\text { transport sector }\end{array}$ & 0.025 \\
\hline & & OP3: Industrial development & 0.025 \\
\hline & & OP4: Employment opportunities & 0.020 \\
\hline & & OP5: Development of Human Resource & 0.020 \\
\hline & & $\begin{array}{l}\text { OP6: Development of coastal/rural } \\
\text { communities and tourism }\end{array}$ & 0.015 \\
\hline & & $\begin{array}{l}\text { OP7: Regional and Extra-regional } \\
\text { integration }\end{array}$ & 0.010 \\
\hline & & OP8: Prospects of cultural connectivity & 0.005 \\
\hline \multirow{5}{*}{ Threats } & \multirow{5}{*}{0.25} & TP1: Terrorism & 0.120 \\
\hline & & TP2: Political instability & 0.070 \\
\hline & & TP3: Conspiracies & 0.020 \\
\hline & & $\begin{array}{l}\text { TP4: Monopolisation in transport segment } \\
\text { (road \& sea based systems) }\end{array}$ & 0.020 \\
\hline & & TP5: Piracy and armed robbery & 0.020 \\
\hline
\end{tabular}


Table 2. A'WOT analysis of China in the context of BRI and CPEC.

\begin{tabular}{|c|c|l|c|}
\hline Swot Group & $\begin{array}{c}\text { Overall } \\
\text { Priority }\end{array}$ & \multicolumn{1}{|c|}{ SWOT Factors } & $\begin{array}{c}\text { Priority's } \\
\text { Score }\end{array}$ \\
\hline \multirow{4}{*}{ Strengths } & \multirow{3}{*}{0.30} & SC1: Sustained economic growth & 0.120 \\
\cline { 3 - 4 } & & SC2: Skilled human resources & 0.060 \\
\cline { 3 - 4 } & & SC3: Major exporting industrial economy & 0.060 \\
\cline { 3 - 4 } & \multirow{4}{*}{ Weaknesses } & SC4: Huge capital resources & 0.060 \\
\hline \multirow{3}{*}{0.20} & WC1: Securing lanes of communication in IOR & 0.060 \\
\cline { 3 - 4 } & & WC2: Consumption of Surplus Output Potential & 0.060 \\
\cline { 3 - 4 } & & WC3: Negative impacts on Xinjiang of China & 0.060 \\
\cline { 3 - 4 } & & WC4 Language Barrier & 0.020 \\
\hline \multirow{3}{*}{ Opportunities } & OC1: Alternate Access to Indian Ocean Region & 0.180 \\
\cline { 3 - 4 } & \multirow{3}{*}{0.40} & OC2: Regional integration & 0.120 \\
\cline { 3 - 4 } & & OC3: Market prospects of cultural connectivity & 0.100 \\
\hline \multirow{3}{*}{0.10} & TC1: Political discontent in Pakistan & 0.040 \\
\cline { 3 - 4 } & & TC2: Regional and internal securities challenges & 0.020 \\
\cline { 3 - 4 } & & TC3: Baluchistan conundrum & 0.020 \\
\cline { 3 - 4 } & & TC4: Terrorism in Pakistan & 0.020 \\
\hline
\end{tabular}

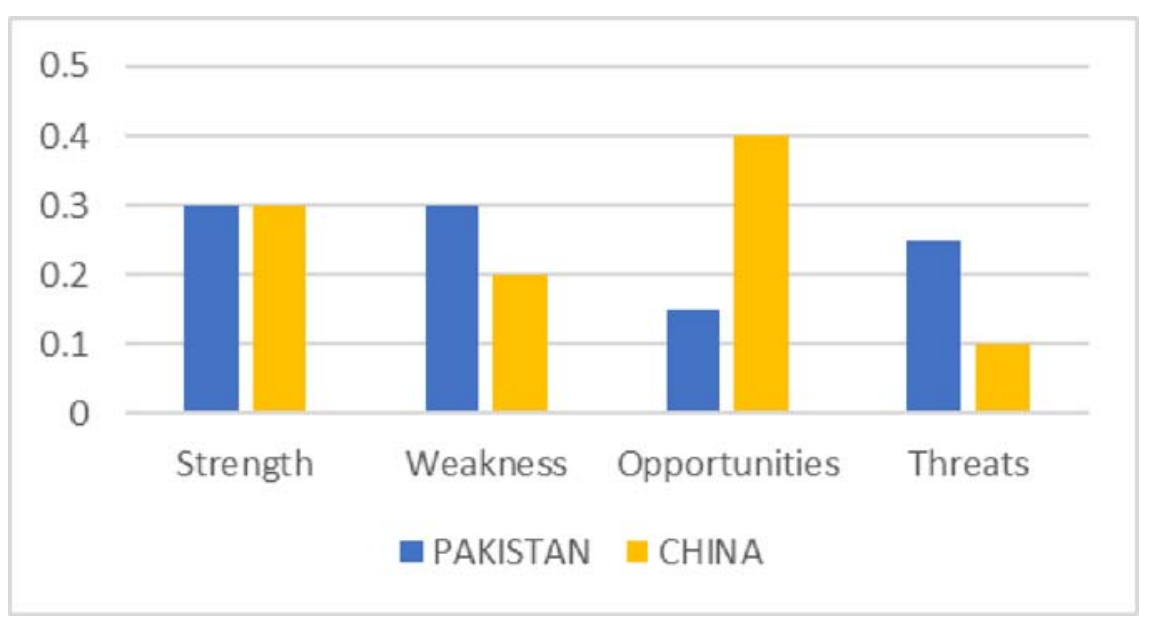

Fig. 2. A'WOT based comparison.

\section{Discussion}

Stakeholders have consensus on the vitality of a stable economy due to its strong linkages with income from trade, development of rural areas and regional integration. The important points of consideration in A'WOT analysis were the aspects of geo-stratic locations, trade flux, investments and participation of different countries, infrastructure development, trust factor of investors, market competitiveness, conspiracies and awareness etc.

\subsection{Strengths}

BRI and CPEC interventions will help China to expand and sustain its extraordinary social and economic development and GDP growth (SC1) that is achieved over the last fifteen years [19]. China is emerged as a major economic global power with its skilled manpower and leading trade role $[20,21]$ across the world along-with having huge capital resources (SC2, SC3 \& SC4). The lion's share of CPEC investments, roughly US\$ 35 billion, is expected to 
go to energy projects including coal, solar, hydroelectric, liquefied natural gas and power transmission system [22]. The Chinese discourse of non-intervention and mutually beneficial policy [23] are attracting large numebr of investors in Pakistan (SC1 \& SC4).

Geographically, Pakistan has strategic significance for regional integration, through BRI and CPEC, from West and Central Asia including Russia, the Persian Gulf and the Middle East (SP1). These interventions would help Pakistan to stabilize the growing Indian influence in the region [24]. Pakistan is 10th largest country of the world regarding human resource capital with two-third of its population below the age of 25 years [19] and having labor cost two times less than India and five times less than China (SP4). In term of GDP growth, Pakistan's economy had an average annual rate of approximately 6\% during 1963 to 1993 [25], and below $6 \%$ over the last decade. Pakistan's export was estimated upto US\$ 28 billion with anticipateed $12.2 \%$ increase during the fiscal year 2018-2019 compare to the surged rate of $12 \%$ for previous year [26]. Fish exports are the major source of foreign revenue from maritime sources in developing countries. Pakistan's marine and freshwater resources contain a huge variety of aquatic fauna [25] that would play significant role to meet the accelerated fish demand due to BRI and CPEC (SP4). Pakistan is a strong and resilient nation that has faced many crises and up heals (SP5). Despite having so many traditional and nontraditional security threats and terrorism in the country, the nation has not given up its ambitions and targets and striving to make the country more prosperous and stable [27].

\subsection{Weaknesses}

USA and China are the biggest maritime trader with nearly $25 \%$ trade share worldwide in which seaborne component very significant. China needs to secure its existing routes (WC1) for smooth Sea Lanes of Communications (SLOCs) in IOR [19]. China applies surplus production approach [28] which is negatively impacting China's economy due to imbalances in supply and demand (WC2), while BRI and CPEC will add more trade flux which needs to be strategized. Terrorism is not only a problem in Pakistan but also exists in China due to separatism movement in some parts of Xinjiang with reasons of least developed area and higher ratio of unemployment (WC3) which needs to be addressed [29]. Language could be another barrier for better communication with Pakistani business community (WC4).

Pakistan has only $6 \%$ skilled ratio of its huge human resource capital (WP3), and shortage of technical and vocational programmes together with job placement (WP1) are key issues under BRI and CPEC scope. There is weak mechanism to curb corruption and transparency which would likely aggravate the problems in the context of CPEC (WP2 \& WP3) as IMF has raised concerns about transparency. Climatic vulnerability is also high in the mountainous areas throughout CPEC alignment (WP4) which needs to be addressed for normal traffic flow [25].

\subsection{Opportunities}

China now believes on regional integration and CPEC offers a great East-West link [30] for peace, prosperity and alternate access (OC1 \& OC2). CPEC's worth under BRI is equivalent to approximately $20 \%$ of Pakistan's annual GDP. It will bring change in the existing transportation patterns. A large segment of seaborne trade will be diverted to land based routes due to distance and cost effectiveness. This route would not only be beneficial for Pakistan but also gives enhanced trade connectivity to China for Europe, America and Africa with reduced distance and security threats due to blockage of Malacca Strait in some unforeseen scenarios [19]. This indicates relatively more opportunities for China than Pakistan (OC1, OC2, OC3, OP3 \& OP7), as shown in Figure 2. 
CPEC projects will support and strengthen both countries in numerous sectors especially in terms of trade, business, infrastructure, energy, transport, as well as social sectors through Gwadar Gateway development and regional integration (OP1-OP8). People-to-People contacts and cultural exchanges would likely promote inter-civilization communication and coordination of diplomatic strategies to build a harmonious neighborhood for enhanced cooperation (OP7 \& OP8) among countries of different civilization. CPEC has the potential to create around 1.2 million jobs and the number may go up (OP4) with the inclusion of new projects under the long-term plan thus help in shrinking the current unemployment rate. It would promote rapid industrialization in Pakistan (OP3) and coastal tourism would likely flourish [28]. Agriculture sector would be direct as well as indirect beneficiary. The underdeveloped and marginalized areas of Baluchistan province will also be uplifted [31]. This indicates overall improvement in socio-economic conditions of rural and coastal communities (OP6).

\subsection{Threats}

Some Chinese investors are worried about circular debt in Pakistan's energy sector that may result in investment losses [4]. Political stability and consensus regarding provincial shares under CPEC projects [32] are important factors (TC1). Regional and internal security challenges could be the biggest threats, specifically in Afghanistan and Baluchistan conundrums (TC2 \& TC3). Balochi people have concerns regarding proper rights. In recent years, terrorists attacked Chinese in Pakistan (TC4) which need proper measures [33].

Gwadar and many CPEC projects are Baluchistan based where some external factors are interfering and trying to manipulate things in future (TP1) to spoil China-Pakistan cooperation [34]. Pakistan is providing security to Chinese workers to make this project successful [9] which needs to be maintained. During 80's and 90's, Pakistan has faced the political instability due to conspiracies and mal-functioning, which has weakened the country's development roadmap and consistency in policy governance [35]. Important features of the ecosystem development should be taken into account [36]. Some methodological issues could include the development of the logistical model for energy projects' investment sources in the transport sector [37]. It cannot be afforded further prior to ensure smooth functioning of CPEC interventions (TP2 \& TP3). Terrorism, piracy, robbery, human trafficking and cybercrimes in the IOR may cause economic disruptions and distress to Pakistan (TP5), China and other stakeholders [7]. Monopolisation is an important aspects in the transport sector. There is a growing fear of market monopolization by the Chinese Shipping operations (TP4) as the existing ships fleet of PNSC does not have the capacity to fulfil requirements of CPEC's market demands which needs to be strengthened and augmented with Pakistani private sector's investments. Pakistan's Road transportation business will be at boom under CPEC with about 100,000 new cargo trucks addition [5]. There is also a likelihood of market monopolization or oligopoly by few entrepreneurs (TP4) which needs to be addressed through encouraging multiplayer and competitive system.

\section{Conclusion}

A'WOT method proved well for situational analysis of strategic affairs of BRI and its offroot interventions under CPEC as it is a course of common benefits and a strategic partnership between China and Pakistan. Results and discussion reveal that the success rate of the interventions will determine the future course of BRI and CPEC. The successful BRI and CPEC endeavours will open up a door for future investment, prosperity and sustainable development in IOR. It will bring the coast of the Indian Ocean to the Chinese sphere of influence and will open up new avenues for employment, development of rural areas, and 
will bring stability in both China-Pakistan. The level of strength of both China and Pakistan is almost same to undertake huge scope of BRI and CPEC. The crown jewel of CPEC is Gwadar port without which BRI is incomplete. As far as opportunities are concerned, China has more avenues compare to Pakistan. There are some challenges in the completion of this project which cannot be neglected. It is found that China has more emphasis on opportunities and believes that regional integration is the important factor for the economy to grow worldwide. Pakistan normally focus on avoiding the weaknesses and threats. Whereas, Pakistan has strategic significance for regional integration, through BRI and CPEC, from West and Central Asia including Russia, the Persian Gulf and the Middle East. However, Pakistan has higher ratio of threats compare to China and relative to the opportunities considering the weaknesses due to internal and external factors. Maritime trade under BRI has success potential due to geo-strategic location of Pakistan and weaknesses can be avoided in a complete decision support manner with appropriate policy and strategic arrangements. Making BRI and CPEC interventions a truly win-win scenario for Pakistan requires risk management strategies to counter the weakness and threats of Pakistan. Pakistan and China need to form a strong collaborative institutional mechanism for smooth and transparent economic dealings.

\section{References}

1. Q. Fatima, A. Jamshed, South Asian Studies 30(2), 73 (2015)

2. N. Khalid, Journal of Political Studies 19(2), 57-69 (2007)

3. T.O.F. Compact, Security 79 (2004)

4. A. Li Xialou, Journal of Contemporary Studies IV(2) (2015)

5. K.M.J. Iqbal, B.B. Haider, Polaris- Journal of Maritime Research (P-JMR) 3(1) (2020)

6. A. Safdar, The China-Pakistan Economic Corridor-Its Maritime Dimension and Pakistan Navy (2016) http://issi.org.pk/wp-content/uploads/2016/05/AiyshaSafdar_Vol.35_No.3_20151.pdf

7. H.Y. Malik, Strategic Importance of Gwadar Port. Pakistan observer (2012) https://www.researchgate.net/profile/Yaser_Malik

8. M.S. Ahmad, F. Asmi, M. Ali, M.M. Rahman, S.M. Abbas, International Journal of Business and Social Research 7(8), 26-42 (2017)

9. M. Abid, A. Ashfaq, Journal of Pakistan Vision 16(2), 142-169 (2015)

10. R.L. Keeney, Value-focused thinking: A path to creative decision-making (Harvard University Press, Cambridge, MA, 1992)

11. M. Pesonen, M. Kurttila, J. Kangas, M. Kajanus, P. Heinonen, Forest Science 47, 534$541(2001)$

12. M. Kajanus, M. Kurttila, J. Kangas, A'WOT method and its recent elaborations in strategic natural management planning processes (2003)

13. M. Pesonen, M. Kurttila, J. Kangas, M. Kajanus, P. Heinonen, Forest Science 47, 534541 (2001)

14. E. Ahlman, Tourism Management 16(6), 447-453 (1995)

15. T.L. Saaty, The analytic hierarchy process. Planning, priority setting, resource allocation (McGraw-Hill, New York, 1980)

16. K.M. Reynolds, The Analytic Hierarchy Process in Natural Resource and Environmental Decision Making (Springer, Dordrecht, 2001) 
17. D. Winterfeldt, W. Edwards, Decision analysis and behavioural research (Cambridge University Press, Cambridge, 1986)

18. P. Leskinen, J. Kangas, Silva Fennica 35, 93-102 (2001)

19. S.U. Rahman, Z. Shurong, Arts Social Sci. J. 8, 284 (2017) doi:10.4172/21516200.1000284

20. A. Daoui, Who is Africa's Largest Trading Partner? Ways To Cap (2018) https://www.waystocap.com/blog/author/amira/page/3/

21. Xinhua, China's foreign trade up $14.2 \%$ in 2017. China Daily (2018) http://www.xinhuanet.com/english/2018-01/12/c_136890444.htm

22. D.S. Markey, J. West, Council on Foreign Relations 5(1) (2016)

23. M. Hameed, Palgrave Communications 4(1), 64 (2018)

24. M. Hussain, S. Mehmood, N. Saeed, Journal of Chinese Studies 5(2), 46-54 (2012)

25. L.N. Al-Mutairi, Exports and Pakistan's economic development. Pakistan Economic and Social Review, 134-146 (1993)

26. A. Hussain, Pak exports surge by $22.54 \%$ in Aug 2018, overall by 5.05\%. Pakistan Today (2018) https://profit.pakistantoday.com.pk/2018/09/11/pak-exports-surge-by-2254-in-aug-2018-overall-by-5-05/

27. A.E. Rafi, Resilience. Pakistan Observer (2016) https://pakobserver.net/resilience/

28. P. Ferdinand, International Affairs 92(4), 941-957 (2016)

29. J. Tschantret, Terrorism and Political Violence, 1-20 (2016)

30. F. Strrasser, China Pakistan economic corridor: A Road to Peace (USIP, 2016)

31. R. Haq, N. Farooq, Pakistan Development Review 56(4), 597-619 (2017)

32. A. Ali, Arts Social Sci. J. 7, 204 (2016) doi:10.4172/2151-6200.1000204

33. G., Majeed, R.S. Hashmi, South Asian Studies 29(1), 1026-678X (2014)

34. A. Riaz, H. Mi, Arts Social Sci. J. 8, 265 (2017) doi:10.4172/2151-6200.1000265

35. M. Mohsin, M. Yongtong, K. Hussain, A. Mahmood, S. Zhaoqun, K. Nazir, W. Wei, International Journal of Marine Science 5 (2015)

36. S.Y. Barykin, I.V. Kapustina, S.M. Sergeev, V.K. Yadykin, Journal of Open Innovation: Technology, Market, and Complexity 6, 1 (2020)

37. O. Kalinina, S. Firova, S. Barykin, I. Kapustina, Development of the Logistical Model for Energy Projects' Investment Sources in the Transport Sector (Springer Verlag, 2020) 